\title{
Research on the innovation of mobile digital multimedia platform
}

\author{
Menglin Liu \\ College of Information Science and Engineering Zao Zhuang University, Zao Zhuang 277100, \\ China
}

906270@qq.com

Keywords: mobile digital, multimedia technology, discipline competition, practice teaching mode

\begin{abstract}
In computer professional teaching, how to improve student's practical ability, creative ability and entrepreneurship ability are the main problems under the new situation that higher education has developed rapidly. In the teaching process, we construct a Mobile digital multimedia platform to apply application of digital multimedia technology. With this platform, we construct and apply the practice teaching mode which combining with the teaching reform and the discipline competition. After practice, the practice teaching mode has improved the students' comprehensive quality, innovative ability and the discipline competition ability.
\end{abstract}

\section{Introduction}

In twenty-first Century, under the new situation of popularization of higher education, the institution of higher education faces some major issues such as adapt to social and economic development needs, scientifically determine the training target, deepen the teaching reform and improve the level of management.

Computer courses has strong the oretical and deep practical. In the current student body, only child is the majority, which main characteristic is the lack of thinking, hands-on ability, strong dependence and the lack of practical ability. Therefore, in the teaching process, we should emphasize the students' interest in training, highlight student's main body status, advocate autonomous learning, cultivate students' innovation ability and independent analysis ability and the ability to solve problems.

With the rapid popularization of mobile phone and intelligent development and the arrival of 4G era, as a teacher should keep pace with the times, timely adjust the practice teaching methods. So I made research of innovations in teaching as follows: through the intelligent mobile communication terminal , use mobile digital media platform, use wireless communication network and mobile computing technology, to integrate and display all kinds of learning information resources and application service to the students, for the majority of students to provide realtime information services, so that not only to stimulate students interest in learning, but also to cultivate the students' ability of autonomous learning, independent analysis and problem solving capacity, in order to improve the students ability of practice and innovation.

This article introduces a bit of superficial view on the practice teaching mode in mobile digital era.

\section{Build Mobile Digital Multimedia Technology Platform, Perfect Discipline Competition System}

According to the students' practical ability, abstract thinking is limited and so on, we have established a mobile digital multimedia experiment platform, which configure the switch, router, wireless equipment, digital camera, video capture card, HD projector and other hardware devices.

With these equipments, we can enable students to participate in academic competitions, make full use of the laboratory conditions and Equipment of portable mobile terminal, and really operate practical equipment,. So we can make theory and practice more closely, and achieve good results.

On the discipline competition system, we take student oriented, fully stimulate enthusiasm for learning, and deepen the reform of experimental teaching. 
There is a good discipline contest tutor team, and they can use the digital multimedia experiment platform to teach the students relative courses, lay a solid foundation for students' ability and competition level.

With good experimental conditions and excellent teaching resources, our college students are actively involved in different levels of discipline competition or technological innovation activities.

With science and technology innovation and subject contest activities, the second classes greatly stimulate the students' innovation consciousness, enthusiasm for learning and practical ability.

Students' will and character have been trained and reflected. Mobile digital multimedia experiment platform promote the boom of the discipline competition, and yield fruitful results.

Subject contest extensively improve teaching quality, promote the curriculum group construction, cultivate the comprehensive quality of students, enrich the teaching means of the experiment, and make the mobile digital multimedia experimental platform construction on a new step.

\section{Use Mobile Digital Multimedia Experiment Platform, Rich Discipline Competition Teaching}

According to the different characteristics of the discipline competition, we adopt a plurality of discipline competition guidance method in the use of mobile digital multimedia experiment platform. Then we gradually cultivate students' independent innovative ability and practical ability.

There are some method has given:

The first method is Demonstration Teaching Type.Firstly, guidance teacher make the problem analysis, explanation. Secondly, student completed the tournament title by the teacher steps independently. In the process, the teacher gives guide and FAQ on the spot. In participating in the national mathematical modeling contest, students only know the mathematical formula of many models of specific graphics and features is not enough. At that moment, teachers use MATLAB mathematical tools to show real-time demonstration of graphic images. It is a great benefit for students' digestion and absorption of knowledge to the visual image.

The second method is Independent Type. When students participate in the countrywide ACM contest competition, the competition is composed of three students in a group, and is completed independently in the absence of teacher involvement. At this time, the student independent thinking, the ability to analyze and solve problems is particularly important. In view of this type of competition,teachers inevitably involve some key algorithms and data structures to explain in the teaching process.Teachers should make full use of multimedia means with graphics, audio, video data on the subject to explain thoroughly on the data structure and algorithm that can't easily understood, and enable the students to grasp the knowledge points deeply.On the basis of this, students should independent preview and analyze before doing tournament title. In combination with the teachers' explanation of knowledge points, students do the experiment independently. Students can do the experiment with problems,solve the problem in the experiment. After exercise, the students' independent analysis of issues and problem-solving ability has been improved. It's laying a good foundation for more students.

The third method is The Group Cooperation Type.Our college students participate actively in the China Qilu Software Design Contest for college students in Shandong Province. There are much knowledge inside of the problem involves a lot of books and courses are difficult to relate or involved. For example, the problem is The Design and Implementation of Olympic Games FUWA or Network Search Engine Design. If there is no good mobile digital multimedia experiment platform based on these issues, it is very difficult to do. In the design process of Olympic Games FUWA, used in the 3DMax model construction and design, this course explanation involves more model construction and aesthetic knowledge. Then guide teachers arrange courses for students after collect relevant materials. In the design process of Internet Search Engine, we make full use of mobile digital multimedia laboratory platform; build good experimental environment, patient and meticulous debug program code on the basis of the combination of software and hardware. These are all inseparable from the use of multimedia technology and platform construction. In the competition process, students are divided into several groups, and then cooperate to complete puzzles. During competence the students in the course decompose their task, arrange division and 
planning schedule, find information, design, discussion and exchange, explore the rule, compose and submit papers.In the process teachers will give the appropriate guidance. Through participation in events, the students cultivate the ability of using knowledge, the ability to analyze and solve problems, the ability of independent research and innovation, but also train the spirit of cooperation in scientific research.

The table I below has presented data before and after training by all kinds of teaching method. Table 1 Student Efficency Data

\begin{tabular}{|l|c|c|}
\hline \multirow{2}{*}{1} & \multicolumn{2}{|c|}{ Student in discipline competition who does well } \\
\cline { 2 - 3 } & Before training & After training \\
\hline Demonstration Teaching Type & $33 \%$ & $56 \%$ \\
\hline Independent Type & $28 \%$ & $61 \%$ \\
\hline The Group Cooperation Type & $25 \%$ & $79 \%$ \\
\hline
\end{tabular}

From the table we can make a conclusion, students who get well training will have plenty of benefit from it.

\section{Based on the Mobile Digital Multimedia Technology Platform,Promote Curriculum Group Construction of the Discipline Contest}

In our practice, we promote the construction of specialties and curriculum teaching reform based on mobile digital multimedia technology platform. It has received the good teaching effect.

As everyone knows, the discipline competition differs from common curriculum teaching system. The number of students is less, require a higher overall quality.

As a local college, we know that, the students can not be compared with some key University. In order to compete with the students within province and even countrywide college student in the same arena, the local students should make full use of the subjective and objective conditions, concentrate advantage power, and dig the potential of their own. The core of discipline competition is analyzing the characteristics and the related courses and research.

The curriculum relates to discipline competition: theory, practice, and theory and practice union. The theoretical course is the course that it's content focus on the theory introduction and analysis, including the curriculum: discrete mathematics, programming language theory, the program design, calculation method, compiler theory, artificial intelligence, computer network, mathematical modeling.

Curriculum of practice refers to the curriculum focuses on the practical operation and application, including the curriculum: webpage making, graphics, animation, computer aided design, manmachine interface and virtual environment technology.

The combination of theory and practice including: principle and application of database system, software engineering, data mining, computer graphics, programming language design.

In view of the special subject contest rule and the characteristic, the students should learn lots of knowledge on the theory and practice of guidance in a short period. Therefore, careful arrangement of the course and articulation, knowledge distribution and difficulty appears more important. Application of multimedia technology in here has played a very important role.

It requests the teacher extract some key, difficulty, key points out by using graphics, audio, video and other multimedia means, so that the students can grasp the solid theoretical foundation and strong practice, practical ability.For example, in the Qilu software design contest ,many courses are arranged in a short span of 2 months, such as" Java programming"," Java programming"," 3D"," Web Service Max design" and other related courses.

We explore the discipline contest course group construction to step delectable one pace, for students to get good grades tamp foundation.

\section{Mobile Digital Multimedia Platform Construction and Discipline Competition Achievements}

Based on the mobile digital multimedia technology platform, with the professional competition and integrated competition, we have achieved good results. 
In the work, we further strengthen the mobile digital multimedia experiment teaching platform construction, provide quality and efficient experimental environment; strengthen the multimedia information platform construction. With rich courses of computer cyber source, facilitate communication between teachers and students and students' Autonomous learning are build.

The computer experimental teaching center was named in Shandong Province demonstration experimental teaching center; it is a sufficient affirmation under the condition of multimedia laboratory platform construction.

Our college students have achieved excellent results in the national mathematical modeling contest, national ITAT skills contest, Qilu Software Design Contest. In the practice teaching system construction as well as the discipline competition, remarkable results are achieved.

Many courses were rated as the academy level courses teaching reform, and over 40 papers are published, teachers were rated as excellent teacher subject competition.

\section{Conclusions}

Along with the mobile digital multimedia experimental platform construction and the various regulations system ceaseless and perfect, the deepening of teaching reform and innovation activities of science and technology more widely, the exploration and construction of curriculum system, teaching methods constantly enriched, students' learning enthusiasm and ability has been improved. This prompts the discipline competition performance to further enhance, in all competitions have achieved good results.We are actively building a mobile digital multimedia platform, applying digital multimedia technology, building and practice of the teaching reform and the discipline competition combining practice teaching mode.

After practice, the practice teaching mode has greatly improved the students' comprehensive quality, innovative ability and discipline competition ability.

The extensive use of mobile digital multimedia technology and discipline competition promote the students comprehensive quality development, improve students comprehensive practical ability and practical ability, has the very high value of promotion.

\section{References}

[1] P.He and Y.Liu: Electronic Technology \& Software Engineering, 2014 No.5, p. 42-43.( In Chinese)

[2] H.L.Ma: Research in Higher Education of Engineering, 2004 No.4, p. 85-86. ( In Chinese)

[3] J.H.Li: Digital Technology And Application 2012 No.10, p. 62. ( In Chinese)

[4] S.B.Li:University Mathematics Vol. 25 (2009) No.5, p.8-10. ( In Chinese)

[5] Z.D.Chen and F. Li: China Education Innovation Herald ,2011 No.02, p. 243-245. ( In Chinese)

[6] Y.Zhang :Computer education 2007 No.10, p. 22-23,75. ( In Chinese)

[7] F.Z.Lin: Fundamentals of multimedia technology(Tsinghua University Press, China 2002). ( In Chinese) 